\title{
Políticas públicas no Brasil: desafios para a participação política e a cidadania
}

\begin{abstract}
Resumo
O presente trabalho se propõe à análise da formulação das políticas públicas no cenário brasileiro contemporâneo. Inicialmente, apresenta-se alguns elementos sociopolíticos da formação do Estado neopatrimonialista brasileiro, por meio da análise weberiana, que postula a sua formação anterior à sociedade. Após, busca-se enriquecer o estudo, relacionando o entendimento sobre esse Estado à análise dos desafios na formulação das políticas públicas, à ampliação da participação política e à construção da cidadania, por meio de pesquisa bibliográfica especializada no tema. A perspectiva de análise está respaldada no arcabouço teórico das Ciências Sociais, que estuda o governo em ação. 0 presente estudo postula, para o caso brasileiro, a construção de uma cidadania frágil, seguida de uma baixa participação social nas políticas públicas, precedida pelo amálgama modernização/tradição do Estado.
\end{abstract}

Palavras-chave: Estado neopatrimonialista. Políticas públicas. Cidadania. Participação política.

\begin{abstract}
The present work proposes the public policies formulation analyzis in the Brazilian contemporary Stage. Initially, we propose some social politics elements of the neopatrimonialist State formation, by means of the weberian analyzis, that postulates to its formation society anticipate. We also intend to improve the study through specialized literature research in the subject and propose our understanding about the logical public policies formulation models, the increase policy participation and the conception of citizenship. To achieve this goal it was used the theoretical social science study that analyzes the government in action. This paper goes to the idea that in Brazilian case it has been

${ }^{1}$ Doutorando e Mestre em Diversidade Cultural e Inclusão Social pela Universidade FEEVALE. Professor do Centro Universitário Metodista do Sul - IPA/Porto Alegre. douglasmarques@feevale.br.

2 Mestre em Diversidade Cultural Inclusão Social pela Universidade FEEVALE. Psicólogo da Prefeitura Municipal de Novo Hamburgo. Membro da Associação Brasileira de Psicologia Social (ABRAPSO).svoboda@svoboda.com.br
\end{abstract}


constructed a fragile citizenship, followed by public policies created from high to above, anticipated by the contemporary conception of Neopatrimonialist State.

Keywords: Neopatrimonialist state. Public policies. Citizenship. Policy participation.

\section{Introdução}

Compreender a formação do Estado e sua relação com as políticas públicas é fundamental para o debate político e democrático no Brasil atual. Para este fim, colocaremos em discussão alguns elementos da formação sociopolítica do Estado brasileiro através do postulado weberiano, o qual relacionaremos com a construção da cidadania e com a formulação das políticas públicas geridas nesse contexto.

Pensando a partir da perspectiva weberiana, conceituaremos a relação entre Estado e sociedade civil dentro de um jogo de poder onde o primeiro se arma de elementos para anteceder as reivindicações e necessidades do outro. Como sugere Santos (2013), o Estado, instituído a partir de um modelo importado, configurou-se como uma entidade anterior e robusta, que foi, paulatinamente, amalgamando a sociedade. Aqui, apontamos para o processo histórico de formação do Estado brasileiro, no que se refere a sua passagem de um modelo político-colonial à construção de um modelo republicano, em que pese a marginalização participativa da sociedade nos processos decisórios políticos. Somado a isso, o desejo de continuidade no poder, por parte dos dirigentes políticos, os quais reforçavam ainda uma forma de administrar baseada na tradição ibérica, de herança lusitano-patrimonial.

A hipótese do trabalho sugere que, no caso brasileiro, a pesada herança das tradições se reatualize no Estado Neopatrimonialista (SCHWARTZMAN, 1982), o qual promove a baixa participação política dos sujeitos e interfere na construção da cidadania, fragilizando o desenvolvimento social nas suas dimensões global, regional e local. TrabaIharemos com o conceito de Estado como um espaço de convergência de interesses de grupos privados e partidos políticos, que se apresentam no decorrer da sua formação e que passam a trazer também desafios históricos a sua modernização, visto a perpetuação da herança conservadora e das tradições do passado.

A problematização sobre a construção da cidadania no Brasil é impulsionada pela concepção de cidadania na encruzilhada (CARVALHO, 2011), aquela de que o Estado teve influência antecipatória na implementação gradativa dos direitos civis, políticos e sociais, a despeito dos interesses da sociedade civil. Sobre esses direitos, vislumbra-se, para o caso brasileiro, primeiro o surgimento dos direitos sociais, seguidos pelos políticos, para, enfim, chegar aos direitos civis (CARVALHO, 2011). Nesse aspecto, verifica-se que a ordem em que os direitos são estruturados influencia a forma como a cidadania vai se estabelecendo. Seguindo essa conceituação, trabalharemos com a ideia de uma baixa participação política da sociedade civil, embora seus esforços, por meio de manifestações públicas e movimentos populares (e sociais) recentes, de influenciar nas decisões políticas. Contudo, não sugerimos o engessamento da participação popular, pelo contrário, queremos sublinhar os obstáculos e as possibilidades vislumbrados pela 
sociedade civil no caminho da reivindicação das demandas sociais.

Como forma de dar sustentação teórica à hipótese da relação entre Estado e sociedade atravessada pelo neopatrimonialismo, estudaremos a formulação das políticas públicas. Esse estudo se dará por meio do arcabouço teórico das Ciências Sociais, na sua vertente que analisa o "governo em ação" (SOUZA, 2006). Com esse suporte sociológico, pretendemos descrever a maneira como tem se dada a construção das políticas públicas no contexto da formação do Estado brasileiro.

Em relação às políticas públicas, partimos do entendimento de que a concepção de Estado influencia diretamente sua formulação, e que a forma de concepção dessas políticas define quais prioridades são elencadas em detrimento de outras. Isso tem sua importância, quando são pensadas, por exemplo, políticas públicas como instrumentos que podem servir para reparar, enfrentar ou (re)produzir as desigualdades sociais.

A problemática que se apresenta, qual seja, a relação entre a formação neopatrimonial do Estado brasileiro e as concepções de cidadania e de políticas públicas, será tratada por meio do diálogo entre diferentes autores com vistas à construção do entendimento sobre o tema. A fim de atingir o objetivo, utilizamos a metodologia da pesquisa bibliográfica, classificada por Gil (2010) como aquela elaborada a partir de material bibliográfico já publicado, referente ao pensamento de determinado autor, e análise das diversas posições relativas ao tema. A construção teórica respaldou- se, como já explicamos, numa literatura especializada, de onde saíram determinados conceitos a saber: o conceito de Estado neopatrimonialista é abordado a partir do arcabouço teórico de Schwartzman (1982); a problematização acerca da construção da cidadania no Brasil está ancorada em Carvalho (2011) e Marshall (1967), e o debate sobre as políticas públicas está em sintonia com as propostas de Caldas (2008), De Paula (2003) e Souza (2006).

\section{Formação do estado brasileiro}

Ao analisarmos a formação do Estado brasileiro, vislumbramos que o caráter folclórico do atraso que se possa carregar não o faz diferente de outros países, como França ou Japão, que possuem fortes traços patrimonialistas (SORJ, 2001). No entanto, a dificuldade dos setores mais pobres da população em se expressar, a impunidade das elites e sua extrema desigualdade social diferenciam o Brasil daqueles outros países. No plano sociopolítico, sugerimos que o patrimonialismo possa vir a ser uma das causas da baixa participação política e promotor de entraves para o processo democrático. Dessa forma, aspectos tradicionais e modernos da formação de um Estado entram em embate.

Remontando o contexto da formação do Estado brasileiro, temos como característica primeira a sua importação pela coroa portuguesa, reproduzindo, consequentemente, as tradições de um Estado patrimonial, caracterizado pela apropriação privada da "coisa pública", com vistas à perpetuação de determinados grupos privados e partidos políticos no poder (SCHWARTZMAN, 1982). Nesse sentido, Fedozzi (1997) vê a formação do Estado brasileiro à margem das revoluções burguesas clássicas e desenvolvido mediante os condicionamentos impostos pelo modelo de dominação patrimonialista-burocrático, herdado da colonização portuguesa. 
Nesse sentido, o binômio tradição/modernidade, no nosso entendimento, torna complexa a análise da formação do Estado brasileiro. Bublitz (2006) observa que a manutenção da escravidão e de certos privilégios da elite agrária tradicional contribuiu para a reiteração de determinadas características conservadoras no Estado. Mesmo a abolição da escravatura, da forma como ocorreu, não gerou a inclusão socioeconômica dos afro-brasileiros. Parafraseando a autora, ao passo que o Estado optava pelo conservadorismo e o mando, suplantando as revoltas populares, a elite dirigente investia na sua própria sobrevivência e reprodução no poder.

Como consequência dessa antecipação do Estado aos anseios da sociedade civil, descreveu Carvalho (2011) que, no Brasil, a concepção de cidadania tem caminhado na contramão dos países cuja concepção de políticas públicas é a das denominadas Welfare State. Assim, temos primeiro o surgimento dos direitos sociais, políticos e, por fim, os civis. Direitos da primeira geração, como os direitos sociais, não estão resolvidos enquanto instrumentos que possam tensionar e responder às expressões da desigualdade social. Em consulta ao Instituto Brasileiro de Geografia e Estatística (IBGE, 2012), baseado em dados do Censo 2010, e ao portal do Ministério do Desenvolvimento Social do Governo Federal - MDS (BRASIL, 2012), temos que o Brasil possui 16,2 milhões de pessoas em situação de extrema pobreza. O MDS definiu como integrantes dessa faixa da população aqueles que vivem com até 77,00 reais por mês. Com relação à educação, somam-se, no Brasil, 14,1 milhões de analfabetos. Analisando apenas as áreas aqui citadas, já podemos inferir o quanto o desenvolvimento social está em descompasso com o nível de crescimento econômico do país, considerando que o Brasil atingiu o posto de sétima maior economia do mundo em 2012.

Por este prisma, é possível apresentar, de forma breve, o entendimento sobre o processo de formação do Estado brasileiro, antecedente à formação da sociedade, pautado pelas heranças patrimonialista, centralizadora e tradicional. A configuração contemporânea do Estado, a saber, em que coabitam o tradicional e o moderno, é posta em debate na seguinte discussão sobre o fenômeno do neopatrimonialismo brasileiro (SCHWARTZMAN, 1982).

\section{Veja-se, a seguir, o tema Estado Neopatrimonialista e participação política.}

No século XIX, a função do Estado moderno tende a se deslocar para o chamado "bem-estar social"3 da sociedade, provendo direitos sociais aos que estavam fora do mercado de trabalho, para que pudessem participar como consumidores do "pacto" de inclusão da nova ordem social (DE PAULA, 2003). Sob esta ótica, inicialmente, exploremos como tem se dado a participação política no Estado, através do conceito de neopatrimonialismo (SCHWARTZMAN, 1982).

O autor analisa a atual formação do Estado pela coexistência de relações tradicionais e modernas, e, nesse sentido, define que

\footnotetext{
${ }^{3}$ Aqui, conforme o modelo keynesiano de gestão do Estado, que, após o período da Grande Depressão (1929), contrariando as teorias sobre os problemas da produção, sugere que estes são da ordem de demanda, portanto, de consumo. Assim, a função da ampliação dos direitos sociais, sobretudo os trabalhistas, segundo a teoria de Keynes, tornaria possível que a grande leva da população desempregada pudesse participar das relações de compra e venda, aquecendo a economia, por meio do consumo (nota dos autores).
} 
o que o patrimonialismo e feudalismo têm em comum, por um lado, e a dominação racional-legal por outro, é o aspecto 'tradicional' do primeiro e 'moderno' do segundo. É importante lembrar aqui o conceito weberiano de tradição, ou seja, '[...] a crença na rotina de todos os dias como forma inviolável de conduta'. No outro extremo, os sistemas modernos seriam aqueles cujas normas seriam "baseadas na validade de um estatuto legal e na 'competência' funcional baseada em regras criadas racionalmente (SCHWARTZMAN, 1982, p. 128).

A estrutura de (re)produção das relações de poder e dominação, permeadas pelo uso das tradições, potencializa-se no Estado contemporâneo, constituindo uma nova qualidade: somando-se à perpetuação das tradições, temos a burocracia racional estatal. Assim, no interior deste fenômeno, encontramos também um novo traço na participação política da sociedade, o qual se apresenta pela isonomia de acesso às suas estruturas, mas mantém rígidas restrições na ordem das tradições e da pessoalidade. Segundo Schwartzman (1982), nas sociedades modernas, a participação é estendida a todos, mas sua forma e intensidade variam. Sendo mais precisos, num esquema de níveis de participação de um a três, sugerido por Bobbio, Matteucci e Pasquino (1998), a participação da população, para o caso brasileiro, parece-nos que tem se restringido ao primeiro nível, chamado de presença política. O Quadro 1 ajuda-nos na análise do fenômeno:

\section{Quadro 1 - Níveis de Participação Política}

\begin{tabular}{|l|l|l|}
\hline Nível de participação & Conceito de participação & \multicolumn{1}{|c|}{ Forma de participação } \\
\hline 2o Nível & Presença política & $\begin{array}{l}\text { Limitada. O sujeito é informa- } \\
\text { do dos processos decisórios } \\
\text { já tomados. Participar de uma } \\
\text { reunião, por exemplo. }\end{array}$ \\
\hline 3o Nível & Ativação política & $\begin{array}{l}\text { Relativa. O sujeito se engaja } \\
\text { em atividades que lhe foram } \\
\text { confiadas, dentro ou fora da } \\
\text { organização. }\end{array}$ \\
\hline
\end{tabular}

Fonte: Bobbio, Matteucci e Pasquino (1998).

Considerando a participação político-social como a ação pública que interfere na organização e/ou distribuição dos recursos do Estado, nosso entendimento sugere que a participação no Estado não tem ultrapassado o acesso formal da população aos espaços políticos; no entanto, a participação nos processos decisórios ainda se encontra bastante fragilizada. A esse respeito, Gonzáles (2011), ao estudar a participação política na América Latina e, consequentemente, a realidade brasileira, afirma que votar, cumprir as leis e pagar impostos é considerado o elemento mais importante, sendo pouco valorizada a participação em organizações sociais e políticas.

Complementa González (2011) que uma tentativa de romper com as relações de 
patrimonialismo, personalismo e clientelismo, no interior do Estado, foi a criação de instrumentos de participação popular. No entanto, estes "[...] servem, na verdade, aos propósitos de controle do governo central sobre a execução de suas diretrizes e orçamento, utilizando a população como instrumento de fiscalização de decisões tomadas de forma centralizadas, sem a partilha de poder" (GONZÁLEZ, 2011, p. 64).

Ampliando o debate, ao atentarmos para a importância do processo de democratização do Estado, a partir de 1988, vislumbramos uma ampliação da participação da sociedade civil por meio da proposição de Projetos de Leis e de Leis Complementares (Lei complementar no 9.709/98). Contudo, verificamos a escassez de iniciativas populares, ao analisarmos a quantidade de projetos de leis apresentados à Câmara Federal dos Deputados. Mesmo com a implantação dos dispositivos jurídicos, fica evidente que a sociedade tem tido dificuldades para se expressar acerca das suas demandas. Passadas mais de duas décadas, temos apenas quatro projetos de iniciativa popular sancionado pelo Senado Federal ${ }^{4}$. Assim, a respeito da baixa participação política, concordamos com Clemente $(2011)^{5}$, quando este afirma que "[...] os avanços sociais em geral foram outorgados pelo Estado, e não conquistados pela luta popular", embora considerando experiências significativas de táticas de experimentação social (BRAGA, 2012), como o período da primavera à brasileira.

Para Braga (2012), a construção da cidadania na contemporaneidade tende à incorporação de novos arranjos sociais, de iniciativas populares espontâneas, enfim, de novas táticas de experimentação social. Citamos como exemplo as manifestações populares iniciadas em Túnis/Tunísia, em 2010, estendendo-se para o Oriente Médio, em 2011, sendo essas denominadas de "primaveras árabes". No Brasil, durante o mês de junho de 2013, reeditamos a noção de "primaveras árabes" com as manifestações populares em todo o país. Esses movimentos populares apresentam novas táticas sociais à construção da cidadania, sendo elas: 1 ) iniciativas nacionais articuladas a movimentos internacionais; 2) iniciativas legitimadas por iniciativas 'apartidárias', com lideranças descentralizadas e 3) iniciativas simultaneamente articuladas, em vários lugares e ao mesmo tempo, por meio do uso de redes sociais.

Dessa forma, numa breve análise da implantação das políticas públicas, entendemos um frágil exercício de participação da população na construção da cidadania. Verificamos o caráter de "antecipação" estratégica do Estado frente aos processos de organização social e de encaminhamento das demandas sociais. De acordo com CarvaIho (2011), temos uma dicotomia entre a estadania versus cidadania. Assim, sugerimos que a construção da cidadania no Brasil, tendencialmente, seguiu uma lógica assimétrica entre Estado e sociedade civil, predominando os arranjos e mecanismos de dominação estatal, fragilizando o exercício da participação política.

\footnotetext{
${ }^{4}$ Sendo elas: Lei no 8.930/94, dos Crimes Hediondos; Lei no 9.840/99, Contra a Corrupção Eleitoral; Lei Completar no 11.124/05, que dispõe sobre o Sistema Nacional de Habitação de Interesse Social (SNHIS), que cria o Fundo Nacional de Habitação de Interesse Social (FNHIS) e Lei Complementar no 135/10, da Ficha Limpa, esta, sendo a única nos últimos 5 (cinco) anos. O leitor pode aprofundar a análise junto ao portal da Câmara Federal dos Deputados, onde pesquisamos sobre as leis de iniciativa popular no Brasil (CÂMARA DOS DEPUTADOS, 2013).

${ }^{5}$ Augusto Clemente. Cientista político, doutorando pela Universidade Federal do Rio Grande do Sul-UFRGS. País só têm quatro leis de iniciativa popular. Entrevista concedida para a revista online Gazeta do Povo em 2 de outubro de 2011 (GAZETA DO POVO, 2013).
} 
Assim, temos alguns dos postulados da formação do Estado brasileiro contemporâneo através do fenômeno do neopatrimonialismo, de seu desdobramento na baixa participação política e da lógica de "cima para baixo" nas ações estatais. Considerando estes aspectos, apresentamos o entendimento sobre a construção da cidadania e a formulação das políticas públicas.

\section{Cidadania e políticas públicas}

No final dos anos 1980, precisamente em 1988, temos legitimada a reforma da Constituição da República Federativa do Brasil, chamada de Constituição Cidadã. Numa primeira leitura sobre o processo, poderíamos avaliar que a construção da cidadania estava sacramentada e, portando, a sua consolidação era um devir da história. Mas, reportando-nos a Carvalho (2011), este nos alerta sobre qualquer antecipação apressada do processo, e esclarece a dialética do devir: a cidadania do papel e a cidadania do cotidiano. Assim, o devir da cidadania não é uma inevitabilidade histórica, mas um longo caminho de uma sociedade civil amadurecida, embora não resolvida nas suas contradições históricas, onde a sucessão dos direitos civis, políticos e sociais é determinante para a cidadania constituinte. Veremos como os direitos se sucedem e constroem a cidadania brasileira, o que está associado ao impacto social que se observa ainda hoje. Sobre isso, verificamos que a desigualdade social, que acompanha esse atravessamento dos direitos, tem se apresentado para as atuais políticas públicas como uma questão de urgente enfrentamento.

Conforme Cardoso de Oliveira (2011, p. 37): “No Brasil pós-escravidão, a cidadania teria tido sempre um status inclusivo [...] embora os direitos fossem distribuídos de forma diferenciada". Utilizando as ideias de Marshall, para a compreensão da construção da cidadania brasileira, conforme Carvalho (2011), vemos que, no Brasil, os direitos se constituíram em uma determinada ordem, o que gerou um tipo de cidadania que se encontra inserida em um sistema que compactua desigualdades e distribui privilégios. Para entender esse contexto, duas diferenças importantes estão relacionadas com o conceito de cidadania construído no Brasil. O autor supracitado aponta que, no Brasil, houve maior ênfase nos direitos sociais, e que isso acarretou outra mudança importante, alterando o percurso dos direitos observados por Marshall, o que acabou, por consequência, modificando a cidadania resultante. Quando os direitos sociais são a base da pirâmide, uma consequência importante é o excesso de valor atribuído ao Poder Executivo. Nos períodos ditatoriais, o Poder Legislativo foi praticamente usurpado de sua funcionalidade, fazendo com que os direitos sociais estabelecidos pelo Estado promovessem uma centralidade no Poder Executivo.

Assinala Carvalho (2011, p. 221):

Essa orientação para o Executivo reforça longa tradição portuguesa, ou ibérica, patrimonialismo. O Estado é sempre visto como todo-poderoso, na pior hipótese como repressor e cobrador de impostos; na melhor, como um distribuidor paternalista de empregos e favores. 
Todos esses fatos fizeram com que, no Brasil, a concepção de política pública fosse associada a privilégio ao invés de direito, o que minou uma conquista democrática e refreou o desenvolvimento de uma cidadania ativa. Com um poder executivo centralizador e uma sociedade que é sistematicamente destituída de seu real direito político, a cidadania esvazia-se e não se fortalece. Nessas condições, não há promoção de justiça social e nem alteração significativa das disparidades da desigualdade social. Assim, verificando a antecipação dos direitos sociais aos direitos civis e políticos, no Brasil, a cidadania se constitui passiva e receptora (CARVALHO, 2011). O que segue a essa colocação é o desprestígio que o Estado tem por parte de seus cidadãos na efetividade dos direitos basilares da cidadania. O cenário aponta para duas consequências principais: uma sociedade civil enfraquecida e um Estado fortalecido, arbitrário e dominador.

Avançando no debate, temos em Cardoso de Oliveira (2011) a contribuição sobre as duas concepções de igualdade no Brasil. Na primeira, como dita a Constituição Federal Brasileira, o tratamento previsto em lei é aplicado para todos. Dessa forma, constituise a isonomia jurídica como primeiro tipo de igualdade. Na segunda, o tratamento diferenciado, dominante nas instituições públicas e no espaço público compartilhado pelos cidadãos, constitui-se outra concepção de igualdade, na qual os direitos envolvidos na cidadania são relativizados. Em outras palavras, Cardoso de Oliveira (2011, p. 37) explica:

Associando a concepção de igualdade como tratamento uniforme à igualdade de direitos, e a concepção de igualdade como tratamento diferenciado à justificação de privilégios, sugeri que a singularidade brasileira estaria na arbitrariedade da definição entre os campos de vigência das duas concepções, ou de uma certa indistinção entre o exercício de direitos e de privilégios, caracterizando a inexistência de um mundo cívico bem conformado entre nós.

A dificuldade de implementar os direitos constitucionais, gerada a partir da tensão entre as 'duas igualdades', sugere uma desarticulação importante. Observa-se aqui, de um lado, uma clivagem que acontece entre o universo discursivo da formulação de políticas públicas e do acesso aos direitos e o campo das interações cotidianas de outro. Discriminações de classe e status são recorrentes quando se considera a possibilidade de uma igualdade baseada em privilégios. Na concepção weberiana trazida por Schwartzman (1982), classe é utilizada para se referir a pessoas que compartilham da mesma oportunidade de acesso a bens de consumo, condições e experiências de vida pessoais em função de seu poder aquisitivo. Já status é uma avaliação social específica, diretamente relacionada com o monopólio na oportunidade de acesso a bens materiais e ideais. Posições de privilégios baseadas em status e classes são características de sociedades vigentes sob um regime neopatrimonialista.

Frente ao debate, o desafio da modernidade se estabelece: vencer as tradições, os costumes e a cultura da dominação, presentes na formação e reprodução do Estado. Um Estado que opera suas ações na lógica dos favores e da dádiva, como entidade bondosa, não é uma entidade que opera na lógica do direito, ou seja, da cidadania. No caso brasileiro, veremos adiante que o Estado, por meio dos instrumentais políticos e, nesse caso, das políticas públicas, vale-se da cultura política tradicional para a sua perpetuação. 


\section{A seguir o tema Políticas públicas: conceito e desdobramentos no Brasil.}

Introdutória ao tema é a implicação da cultura política nos processos de implantação e participação nas políticas públicas. Gonzáles (2011) defende que qualquer engenharia institucional não deveria ser feita de forma abstrata, sem levar em conta os elementos fundamentais da análise de sua viabilidade de sucesso: as tradições, as condições sociais e o desenvolvimento regional do local em que serão implantadas. Este processo local de reprodução da cultura deve ser incorporado quando da decisão do Estado de implantar e/ou de mensurar os impactos de uma política pública. Aqui, neste trabalho, entendendo o poder executivo local como uma fração do Estado nacional, as ações de ampliação da cidadania pelos pressupostos da modernidade são tensionadas pela cultura da herança da solidariedade tradicional. Assim, as tentativas de operar uma política pública pelos postulados da racionalidade, da democracia, do uso dos espaços públicos, entre outros, estarão perpassadas por ações motivadas pelo perfil carismático/afetivo, pela ajuda dos ricos aos mais pobres, pela manutenção da hierarquia social.

Sobre o conceito de políticas públicas na contemporaneidade, atentamos para Souza (2006), que, ao analisar a formulação dessas políticas na América Latina, salienta uma característica político-cultural relevante: a inexistência de coalizões e/ou polarizações políticas. Essa fragilidade torna-se um entrave às políticas públicas capazes de equacionar crescimento econômico e as demandas nacionais, tornando-se frágil o tensionamento social por uma agenda de demandas sociais da população. Nossa matriz de análise das políticas públicas, sugerida por Souza (2006), está ancorada nos pressupostos das Ciências Sociais, que buscam compreender como e por que os governos optam por determinadas ações. Sugerimos esta vertente de análise em sintonia com o contexto da formação do Estado brasileiro, considerando, como dito anteriormente, que este antecede a formação da sociedade civil. Assim, qualquer teoria de políticas públicas precisa também explicar as inter-relações entre Estado, política, economia e sociedade (SOUZA, 2006).

A experiência particular da ampliação dos direitos sociais no Brasil, seguida ora de um esvaziamento político das instituições, ora do deslocamento político de atores sociais do lugar do tensionamento para a representação institucional/estatal, contribuiu para a baixa participação política da sociedade, não acompanhando o crescimento econômico. Como consequência, não possibilitou: (a) a incorporação de novos contingentes sociais; (b) um maior nível de igualdade social, pois ficaram excluídos os direitos sociais dos "précidadãos" (FEDOZZI, 1997).

As análises sobre os postulados de cidadania, democracia e justiça social que passam a nortear as políticas públicas não podem perder de vista que estas são instrumentos que vão dar forma e conteúdo às agendas e intenções de um determinado governo por meio de programas, projetos e ações governamentais. Dito isso, nosso entendimento sobre políticas públicas sugere que elas não são instrumentos diretos dos anseios societários por democracia e justiça social, mas são permeadas pelas intenções e prioridades de governo, que pretende responder a um determinado fim. Caldas $(2008$, p. 5) contribui com o assunto ao analisar a relação do Estado brasileiro com as políticas públicas na contemporaneidade: 
Políticas Públicas são a totalidade de ações, metas e planos que os governos (nacionais, estaduais ou municipais) traçam para alcançar o bem-estar da sociedade e o interesse público. É certo que as ações que os dirigentes públicos (os governantes ou os tomadores de decisões) selecionam (suas prioridades) são aquelas que eles entendem serem as demandas ou expectativas da sociedade. Ou seja, o bem-estar da sociedade é sempre definido pelo governo e não pela sociedade. Isto ocorre porque a sociedade não consegue se expressar de forma integral.

Para tanto, lançamo-nos a compreender como se dá a natureza das políticas públicas no cenário brasileiro, constituído por um governo denominado democrático -popular, que, nos últimos anos, tem se notabilizado pela efervescência na formulação dessas políticas. Mas aqui, neste construto, sugerimos que sua quantidade precisa ser aferida com os seus objetivos e a qualidade da participação social; assim, a sua qualidade torna-se uma possibilidade.

A nossa análise sugere as políticas públicas de natureza redistributiva (SOUZA, 2006, p. 29), que tendem a incorporar parcelas da população historicamente marginalizadas do acesso aos bens e consumo produzidos pela sociedade, em detrimento de outros extratos sociais. A respeito dessa realidade, a autora supracitada sugere que:

[...] atinge maior número de pessoas e impõem perdas concretas e no curto prazo para certos grupos sociais, e ganhos incertos no futuro para outros; são, em geral, as políticas sociais universais, o sistema tributário, o sistema previdenciário e são as de mais difícil encaminhamento.

Ao caráter impreciso dos encaminhamentos e do 'futuro' das políticas públicas dessa natureza, contrapomos os aspectos cultural da sociedade e político-organizacional das instituições e dos governos. Entendemos as políticas públicas como um marco jurídico-legal, permeadas pelas "inserções" nas relações sociais de uma sociedade, atravessando a cultura instituída e os acirramentos de uma nova cultura; a burocracia e o personalismo das instituições, que moldam padrões na sua cultura organizacional e, ain$\mathrm{da}$, as diferentes estratégias dos governos para atingir determinados fins. A este último item, cabe-nos a indagação: o que leva o governo a optar por uma determinada política pública em detrimento de outra? Na contribuição de Souza (2006), temos três respostas possíveis: 1) A focalização dos problemas, o governo assume que deve fazer algo; 2) A consciência coletiva de uma sociedade que entende que é preciso enfrentar determinado problema. A força ou a fraqueza de tensionamento de grupos e movimentos sociais é determinante na constituição da agenda política; 3) A importância dos participantes, sendo eles visíveis (grupos sociais, mídia, partidos) e invisíveis (intelectuais e burocratas). Os primeiros definem a agenda, cabendo aos segundos suas alternativas.

Nessa questão, entendemos também que o perfil da governabilidade que envolve as decisões dos governos deve ser incorporado na análise. Os democráticos entendem que agregar o maior número de representação da sociedade pode ajudar a compreender melhor o problema. Já os que têm na racionalidade os seus postulados, buscam, entre os envolvidos da sua confiança (do governo), quem reúne as melhores virtudes para enfrentar o problema. E, por fim, temos os chamamos empreendedores políticos, responsáveis pelas estratégias que subsidiam os governos na escolha das políticas pú- 
blicas. Para o convencimento deste grupo decisório, Souza (2006, p. 32) evidencia que:

Existiriam três principais mecanismos para chamar a atenção dos decisores e formuladores de políticas públicas: (a) divulgação de indicadores que desnudam a dimensão do problema; (b) eventos tais como desastres ou repetição continuada do mesmo problema; e (c) 'feedback', ou informações que mostram as falhas da política atual ou seus resultados medíocres.

No caso brasileiro, o cenário atual das políticas públicas tem se pautado por dois conceitos: o de eficiência e controle social. O primeiro, a partir do processo global de otimização dos recursos para a ação dos Estados, em que a administração pública tem se pautado pela teoria do gerencialismo público (BRESSER-PEREIRA, 2011), racionalizando os gastos públicos e visando ao controle fiscal, à maior eficiência e à descentralização estatal. A eficiência passa a ser a nova ordem: otimizar atividades, reduzindo os seus custos. O segundo, o controle social, tem fomentado a participação da população na gestão e avaliação das políticas públicas com vistas ao desenvolvimento social e regional. Este tem sido um instrumento insuficiente no que se refere ao alcance dos seus fins. No Brasil, são exemplos dessa tentativa os diversos conselhos comunitários voltados para as políticas sociais, assim como o orçamento participativo (SOUZA, 2006), que, na sua maioria, não tem possibilitado o acompanhamento "de perto" das políticas públicas pela população e tem se limitado a instrumentos que possibilitam decisões já direcionadas à população.

Dito isso, observar os aspectos da cultura política, da insipiente polarização política e o perfil dos governantes, que são determinantes na formulação das políticas públicas, como já salientado, é de fundamental importância. Souza (2006) ressalta que, embora tenha impactos de curto prazo, essas políticas têm desdobramentos a longo prazo. A autora ainda sugere que não só os indivíduos que têm força, mas as regras formais e informais das instituições (neoinstitucionalismo), bem como os processos de desenvolvimento regional, influenciam diretamente nas políticas públicas.

\section{Considerações finais}

Com o presente estudo, buscamos explicitar o nosso entendimento sobre a relação entre Estado e sociedade civil, que, por um longo período, foi pautada na reprodução das tradições, numa perspectiva weberiana, e que, na contemporaneidade, comunga com o aspecto burocrático-racional, constituindo o fenômeno do neopatrimonialismo. Como desdobramento dessa pesada herança tradicional na formação do Estado, conserva uma estrutura pouco acessível a um contingente significativo da população, o que repercute na sua dificuldade de se expressar por meio das políticas públicas.

Como resultado dessa relação, no caso brasileiro, surge uma cidadania que se desenvolve por meio da antecipação histórica do Estado em relação às demandas da sociedade, caracterizando-a como frágil e com baixa participação social. Quanto ao futuro, vislumbramos uma encruzilhada: as possibilidades de uma cidadania como exercício prático no cotidiano, ou em suas nuances de "igualdade", que não transcendem a isonomia jurídica. 
Por fim, atentando para as políticas públicas, temos uma fragilidade de coalizações políticas na sociedade capazes de tensionar as demandas sociais. O problema se amplifica quando essas políticas são formuladas, na sua maioria, pela lógica da formação do Estado brasileiro: a baixa participação da sociedade e a herança político-cultural que torna o seu acesso privado. Esse cenário indica que a construção da cidadania e a formulação das políticas públicas se apresentam instrumentalmente frágeis para o aprofundamento da democracia e o desenvolvimento regional.

\section{Referências}

BOBBIO, N; MATTEUCCI, N; PASQUINO, G. Dicionário de Política. 11. ed. Brasília: UNB, 1998.

BRAGA, J. B. II Seminário Observatórios, Metodologias e Impactos nas Políticas Públicas. Palestra: Observatórios sociais e as políticas públicas: desafios e possibilidades. Universidade do Vale do Rio dos Sinos - UNISINOS. Dias 27 e 28 de novembro de 2012.

BRASIL. Ministério do Desenvolvimento Social e Combate à Fome. 2012. Relatório Nacional Programa Bolsa Família. Disponível em:

<http://www.mds.gov.br/bolsafamilia>. Acesso em: 31 maio 2012.

BRESSER-PEREIRA, L.C. O Brasil e o Novo Desenvolvimentismo. Revista Interesse Nacional, São Paulo, ano 5, n. 17, p. 76-85, abr./jun. 2011.

BUBLITZ, J. Entre a tradição e a modernidade: dilema do desenvolvimento no Brasil. Santa Cruz do Sul: EDUNISC, 2006.

CALDAS, R. W. Políticas Públicas: conceitos e práticas/supervisão. Belo Horizonte: Sebrae/MG, 2008.

CÂMARA DOS DEPUTADOS. Disponível em: <http://www2.camara.leg.br>. Acesso em: 21 jan. 2013.

CARDOSO DE OLIVEIRA, L. R. Concepções de igualdade e cidadania. Revista Contemporânea, UFSCar, n. 1, p. 35-48, jan./jun. 2011.

CARVALHO, J. M. Cidadania no Brasil. Rio de Janeiro: Civilização Brasileira, 2011.

DE PAULA, A. P. P. Por uma nova gestão pública. Rio de Janeiro: FGV, 2003.

FEDOZZI, L. Orçamento Participativo. Reflexões sobre a experiência de Porto Alegre. Rio de Janeiro: Tomo Editorial, 1997.

GAZETA DO POVO. País só têm quatro leis de iniciativa popular. Disponível em: <http://www.gazetadopovo.com.br/vidapublica/conteudo.phtml? $\mathrm{id}=1175608$ \&tit=Pais-so-tem-4-leis-de-iniciativa-popular>. Acesso em: 21 jan. 2013.

GIL, A. C. Como elaborar projetos de pesquisa. 5. ed. São Paulo: Atlas, 2010. 
GONZÁLES, R. S. Democracia, cultura política e experiências participativas na América Latina. In: BAQUERO, M. Cultura(s) Política(s) e Democracia no século XXI na América Latina. Porto Alegre: UFRGS, 2011.

INSTITUTO BRASILEIRO DE GEOGRAFIA E ESTATÍ́STICA. IBGE. Censo Demográfico 2010. Disponível em: <http://www.ibge.gov.br/home/estatistica/populacao/censo2010/ default.shtm>. Acesso em: 31 maio 2012.

MARSHALL, T. H. Cidadania, classe social e status. Rio de Janeiro: Zahar, 1967.

SANTOS, E. Democracia e desenvolvimento: desafios da sociedade gaúcha. Ijuí: Unijuí, 2013

SCHWARTZMAN, S. Bases do autoritarismo brasileiro. 3. ed. São Paulo: Campos, 1982.

SORJ, B. A nova sociedade brasileira. 2. ed. Rio de Janeiro: Jorge Zahar, 2001.

SOUZA, C. Políticas Públicas: uma revisão da literatura. Revista Sociologias, Porto Alegre, ano 8, n. 16, p. 20-45, jul./dez. 2006. 